RESEARCH ARTICLE

\title{
Molecular and phylogenic identifications of potential herbicide degrading microorganisms from contaminated farmland in Keffi, Nasarawa State, Nigeria
}

\author{
Makwin Danladi Makut* and Murtala Zaharadeen Ibrahim
}

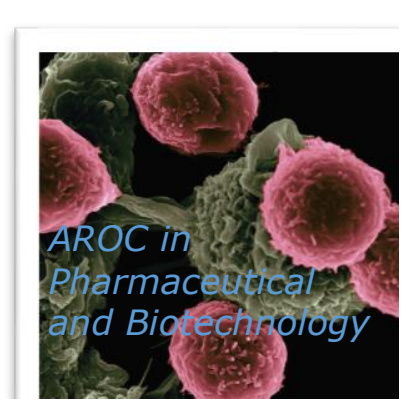

Department of Microbiology, Nasarawa State University, P.M.B. 2022, Keffi, Nigeria

*Corresponding author

Prof. Makwin Danladi Makut

Department of Microbiology, Nasarawa State University,

P.M.B. 2022, Keffi, Nigeria

Email: makmakwin@yahoo.com

\begin{abstract}
Background: Over the past years, the continuous use of herbicides has raised increasing concern mainly due to their massive pollution of the environment. To address this problem, the herbicide-degrading microorganism might be very promising. Method: In the present study, a total of twenty (20) soil samples were collected, bacteria and fungi were isolated from the soil and identified using standard microbiological and molecular studies. Results: The results revealed that a total of 2 bacterial (Enterobacter asburiae and Pseudomonas aeruginosa) and 2 fungi (Aspergillus flavus and Fusarium redolens) strains were isolated from the soil samples collected from herbicide contaminated soil in Keffi, Nasarawa State, Nigeria. The E. asburiae and $P$. aeruginosa had $75.0 \%$, and $100 \%$ occurrence while the fungi isolates including the $A$. flavus and $F$. redolens had $75.0 \%$, and $100 \%$ occurrence respectively. The $16 \mathrm{~S}$ rDNA and ITS1F analysis confirmed the identity of the bacteria and fungi genus. Phylogenetic analysis suggested the bacteria strains were closely related to Pseudomonas aeruginosa strain CIFRI DTSB1 and Enterobacter sp revealed a close relatedness with Enterobacter asburiae RD-DAROS-04 strain, whereas, the fungi strain revealed a closely relatedness of Fusarium redolens strainTIST190421511. Conclusion: In conclusion, the microbial strains including Pseudomonas aeruginosa strain CIFRI DTSB1, Entrobacter asburiae RD-DAROS-04, and Fusarium redolens strainTIST190421511 were the major microbial habitant of pesticide-contaminated farmland in Keffi, and thus represent the herbicide degrading microorganism in this region. Further studies on the herbicide degrading properties of these microbial strains are underway.
\end{abstract}

Keywords: Herbicide; Bacteria and Fungi Isolate; Farmland; Keffi, Nasarawa State; Nigeria

Received: 24 May 2021, Revised: 23 June 2021, Published: 28 June 2021

Citation: Makut, M.D., and Ibrahim, M.Z. (2021). Molecular and phylogenic identifications of potential herbicide degrading microorganisms from contaminated farmland in Keffi, Nasarawa State, Nigeria. AROC in Pharmaceutical and Biotechnology, 01(01);17-25

\subsection{Introduction}

The level of microbial diversity in the soil exceeds that of any other habitat on earth, with density estimates of $10^{9}$ to $10^{10}$ cells per gram of soil [1]. The soil environment supports active microbial growth that contributes to global elemental cycling and makes nutrients available to plants [1]. Simply put, without soil microbes, there would be no plants, which would eliminate herbivores, and so on up the food chain [3]

Biodegradable matter is generally organic material that serves as a nutrient for microorganisms [4].
Microorganisms are so numerous and diverse that a huge range of compounds is biodegraded, including hydrocarbons (e.g oil), polychlorinated biphenyls (PCBs), polyaromatic hydrocarbons (PAHs), pharmaceutical substances [5].

The degradation rate of many organic compounds is limited by their bioavailability. Compounds must be released into solution before organisms can degrade them [6]. The metabolic activities of microbes can also be exploited to carry out biodegradation, bioremediation, and environmental maintenance processes; and the addition of microorganisms to soils or plants for the improvement of crop production [3] 
Herbicides cause a range of health effects ranging from skin rashes to death [7]. The pathway of attack can arise from intentional or unintentional direct consumption, improper Agricultural application resulting in the herbicide coming into direct contact with people or wildlife, inhalation of aerial sprays, or food consumption prior to the labeled preharvest interval [8]. According to the World Health Organization herbicide e.g 2,4dichlorophenoxyacetic acid $(2,4-D)$ is regarded as a hormonal herbicide of high toxicity. It is considered a carcinogenic agent, affecting the liver, heart, and central nervous system, leading to convulsion [9].

The various biological systems, as microorganisms have been used to biotransform herbicides. The bacteria and fungi are the major entities involved in herbicide biodegradation [10]. However, the transformation of such compounds depends on the presence and genetic species of the microorganisms with appropriate degradation enzymes system, in addition to environmental parameters [11]

Fungi and bacteria are in principle abundant in soil and potentially able to degrade herbicides for unknown reasons [12]. This may be related to the observation that microbial degradation appears to stall at low herbicide concentrations in low-nutrient environments such as groundwater [13]. As yet, very little is known about herbicide biodegradation in arable soil under environmental conditions. The present study their fore was set out to conduct a physiological, biochemical, molecular, and phylogenic identification of herbicide degrading microorganisms from contaminated soil in Keffi, Nasarawa State, Nigeria

\subsection{Materials and Method}

\subsection{Description of the study area}

This study was carried out in Nasarawa State University, Keffi, Nigeria. Keffi is located between longitude $8.55^{\circ}$ and latitude $7^{\circ} \mathrm{N}$ and above the sea level of $630 \mathrm{~m}$. Keffi is approximately $53 \mathrm{~km}$ away from the Federal Capital Territory Abuja and $133 \mathrm{~km}$ away from the state capital, Lafia.

\subsection{Sample Collection}

Soil samples for this study were collected from four (4) different farm locations in Nasarawa State University, Keffi, Nasarawa State, Nigeria. Samples were conducted as described by Makut and Bello [14]. The topsoil of (5-10 cm depth) was collected using a sterile spatula and transferred into sterile polythene bags which were transported to the laboratory for further analysis

\subsection{Isolation of Bacteria and Fungi isolates}

Bacteriological media that were used in this study include Nutrient agar (NA), McConkey Agar (MCA), Nutrient broth (NB), Mineral salt agar. Mycological media such as Sabourode Dextrose Agar (SDA), Potato Dextrose Agar were used. All the media were sourced from Oxoid Ltd. (UK). One (1.0) gram of the soil sample was weighed using a weighing balance and was suspended in $9 \mathrm{ml}$ of sterile water. It was properly mixed and a 10 -fold serial dilution was carried out into seven dilutions. $1 \mathrm{ml}$ of the soil suspension was transferred into the test tube containing $9 \mathrm{ml}$ sterilized water and another $1 \mathrm{ml}$ from the $1^{\text {st }}$ test tube was transferred to the $2^{\text {nd }}$ test tube containing $9 \mathrm{ml}$ sterilized water this step was repeated to the $10^{\text {th }}$ test tube.

The diluted samples from $10^{-4}$ to $10^{-7}$ were plated on sterile prepared nutrient agar and yeast malt extract agar by spread plate method and incubated at $37^{\circ} \mathrm{C}$ for 48 hours for bacteria and Sabourode Dextrose Agar for 5 days at ambient temperature for fungi. The isolates were sub-cultured on nutrient agar which were grown and stored on agar slants in the Refrigerator at $4^{\circ} \mathrm{C}$ as the stock culture for further identification [14]

\subsection{Morphological and Biochemical Identification of bacteria Isolates}

The pure cultures were identified based on their cultural, morphological, and Biochemical test (Indole, Voges-Proskauer, methyl red, citrate utilization, catalase, nitrate reduction, urease, sugar fermentation, and starch hydrolysis test as described by Damales and Eleftherohorinos [15].

\subsection{Morphological and Biochemical Identification of the Fungi isolate}

Fungi isolates identification was carried out as described by Makut and Ekeleme [16]. Identification was based on microbiological standard procedure using cultural and morphological characteristics. The cultural characteristics were determined by their appearance on culture plates while the morphological features were determined microscopically using lactophenol in cotton blue staining technique. The isolates were identified with reference to the work of Singh et al. (2011) fungi standard chart. 


\subsection{Molecular Identification of Bacteria Isolates}

Bacterial genomic DNA extraction: Five milliliters of an overnight broth culture of the bacterial isolate in Luria Bertani (LB) was spun at $14000 \mathrm{rpm}$ for $3 \mathrm{~min}$. The cells were re-suspended in 500ul of normal saline and heated at $95^{\circ} \mathrm{C}$ for 20 min. The heated bacterial suspension was cooled on ice and spun for $3 \mathrm{~min}$ at $14000 \mathrm{rpm}$. The supernatant containing the DNA was transferred to a $1.5 \mathrm{ml}$ microcentrifuge tube and stored at $-20^{\circ} \mathrm{C}$ for other downstream reactions.

DNA quantification: extracted genomic DNA was quantified using the Nanodrop 1000 spectrophotometer. The software of the equipment was launched by double-clicking on the Nanodrop icon. The equipment was initialized with $2 \mathrm{ul}$ of sterile distilled water and blanked using normal saline. Two microliters of the extracted DNA were loaded onto the lower pedestal; the upper pedestal was brought down to contact the extracted DNA on the lower pedestal. The DNA concentration was measured by clicking on the "measure" button.

16S rRNA Amplification: The primers used for the amplification of the 16s rRNA region of the rRNA genes of the isolates are presented in table 1 . The gene was amplified using an ABI 9700 Applied Biosystems thermal cycler at a final volume of 50 microlitres for 35 cycles. The PCR mix included: The X2 Dream Taq Master mix supplied by Inqaba, South Africa (Taq polymerase, dNTPs, $\mathrm{MgCl}$ ), the primers at a concentration of $0.4 \mathrm{M}$, and the extracted DNA as a template. The PCR conditions were as follows: Initial denaturation, $95^{\circ} \mathrm{C}$ for 5 minutes; denaturation, $95^{\circ} \mathrm{C}$ for 30 seconds; annealing, $52^{\circ} \mathrm{C}$ for 30 seconds; extension, $72^{\circ} \mathrm{C}$ for 30 seconds for 35 cycles and final extension, $72^{\circ} \mathrm{C}$ for 5 minutes. The product was resolved on a $1 \%$ agarose gel at $120 \mathrm{~V}$ for 15 minutes and visualized on a UV transilluminator.

Table 1: The forward and reversed primers used for the bacterial and fungi gene amplification

\begin{tabular}{|l|l|l|}
\hline Primer types & 16s RRNA & ITS1F: \\
\hline Forward primer & 5'-AGAGTTTGATCMTGGCTCAG-3' & 5'-CTTGGTCATTTAGAGGAAGTAA-3' \\
\hline Reversed primer & 5'-CGGTTACCTTGTTACGACTT-3' & 5'- TCCTCCGCTTATTGATATGC-3, \\
\hline
\end{tabular}

\subsection{Molecular Identification of fungi Isolates}

Fungal genomic DNA extraction: Extraction was done using a ZR fungal/bacterial DNA miniprep extraction kit supplied by Inqaba South Africa. Heavy growth of the pure culture of the fungal isolates was suspended in 200 microlitres of isotonic buffer into a ZR BashingBead Lysis tubes, 750 microlitres of lysis solution were added to the tube. The tubes were secured in a bead beater fitted with a $2 \mathrm{ml}$ tube holder assembly and processed at maximum speed for 5 minutes. The ZR bashing bead lysis tube was centrifuged at $10,000 \mathrm{rpm}$ for 1 minute.

Four hundred (400) microlitres of supernatant were transferred to a Zymo-Spin IV spin Filter (orange top) in a collection tube and centrifuged at $7000 \mathrm{rpm}$ for 1 minute. One thousand two hundred (1200) microlitres of fungal/bacterial DNA binding buffer was added to the filtrate in the collection tubes bringing the final volume to 1600 microlitres, 800 microlitres were then transferred to a Zymo-Spin IIC column in a collection tube and centrifuged at $10,000 \mathrm{rpm}$ for 1 minute, the flow-through was discarded from the collection tube.

The remaining volume was transferred to the same Zymo-spin and spun. Two hundred (200) microlitres of the DNA Pre-Was buffer were added to the Zymospin IIC in a new collection tube and spun at $10,000 \mathrm{rpm}$ for 1 minute followed by the addition of 500 microlitres of fungal/bacterial DNA Wash Buffer and centrifuged at $10,000 \mathrm{rpm}$ for 1 minute.

The Zymo-spin IIC column was transferred to a clean 1.5 microlitre centrifuge tube, 100 microliters of DNA elution buffer were added to the column matrix and centrifuged at $10,000 \mathrm{rpm}$ microliter for 30 seconds to elute the DNA. The ultra-pure DNA was then stored at -20 degrees for other downstream reactions. 
Internal Transcribed Spacer (ITS) Amplification: The ITS region of the rRNA genes of the isolates were amplified using an ABI 9700 Applied Biosystems thermal cycler at a final volume of 50 microliters for 35 cycles. The PCR mix included: The X2 Dream Taq Master mix supplied by Inqaba, South Africa (Taq polymerase, dNTPs, $\mathrm{MgCl}$ ), the primers at a concentration of $0.4 \mathrm{M}$, and the extracted DNA as a template. The PCR conditions were as follows: Initial denaturation, $95^{\circ} \mathrm{C}$ for 5 minutes; denaturation, $95^{\circ} \mathrm{C}$ for 30 seconds; annealing, $53^{\circ} \mathrm{C}$ for 30 seconds; extension, $72^{\circ} \mathrm{C}$ for 30 seconds for 35 cycles and final extension, $72^{\circ} \mathrm{C}$ for 5 minutes. The product was resolved on a $1 \%$ agarose gel at $120 \mathrm{~V}$ for 15 minutes and visualized on a UV transilluminator.

\subsection{Gene Sequencing:}

Sequencing was done using the BigDye Terminator kit on a 3510 ABI sequencer by Inqaba Biotechnological, Pretoria South Africa. The sequencing was done at a final volume of $10 \mathrm{ul}$, the components included 0.25 ul BigDye $\AA$ terminator $\mathrm{v} 1.1 / \mathrm{v} 3.1,2.25 \mathrm{ul}$ of $5 \times$ BigDye sequencing buffer, 10uM Primer PCR primer, and 2-10ng PCR template per $100 \mathrm{bp}$. The sequencing condition was as follows 32 cycles of $96^{\circ} \mathrm{C}$ for $10 \mathrm{~s}, 55^{\circ} \mathrm{C}$ for $5 \mathrm{~s}$, and $60^{\circ} \mathrm{C}$ for $4 \mathrm{~min}$.

\subsection{Phylogenetic Analysis}

Obtained sequences were edited using the bioinformatics algorithm Trace edit, similar sequences were downloaded from the National Center for Biotechnology Information (NCBI) database using BLASTN. These sequences were aligned using ClustalX. The evolutionary history was inferred using the Neighbor-Joining method in MEGA 6.0 [17]. The bootstrap consensus tree inferred from 500 replicates [18], is taken to represent the evolutionary history of the taxa analyzed. The evolutionary distances were computed using the Jukes-Cantor method [19].

\subsection{Results}

\subsection{Isolation and Identification of Fungi and Bacteria Species}

The cultural and morphological characteristics of fungi isolates, as well as the cultural, biochemical, and morphological characteristics of bacteria isolated from the farmland soil, are shown in Tables 2 and 3 respectively. The identified bacteria species included Enterobacter asburiae and Pseudomonas aeruginosa while A.flavus and Fusarium redolens w ere the identified fungi isolates from the farmland soil.

The percentage occurrence of bacteria and fungi species is presented in table 4: Enterobacter asburiae and Pseudomonas aeruginosa had $75.0 \%$, and $100 \%$ occurrence respectively while the fungi isolate including the Aspergillus flavus and Fusarium redolens had $75.0 \%$, and $100 \%$ occurrence respectively.

\subsection{Molecular identification of the bacteria and fungi isolates}

The molecular identification of the bacterial and fungi isolates is shown in Figures 1 and 2 respectively. Agarose gel electrophoresis identified the bands corresponding to the 16S rRNA gene of Pseudomonas aeruginosa and Enterobacter asburiae (figure 1). In addition, the agarose gel electrophoresis revealed the amplified ITS fragment of Aspergillus flavus and Fusarium Redolens (figure 2).

\subsection{Phylogenic and evolutionary tend of the bacteria and fungi isolates}

The 16s rRNA and ITS sequence of the bacteria and fungi isolates produced an exact match during the mega blast search for highly similar sequences from the NCBI non-redundant nucleotide (nr/nt) database. The 16S rRNA and ITS of the isolate showed a percentage similarity to other species at $99-100 \%$.

The evolutionary distances computed using the Jukes-Cantor method were in agreement with the phylogenetic placement of the 16S rRNA isolates within the Pseudomonas sp and revealed a close relatedness with Pseudomonas aeruginosa strain CIFRI DTSB1, while the Enterobacter sp revealed a close relatedness with Enterobacter asburiae RDDAROS-04 strain (Figure 3). The ITS of the isolates within the Aspergillus sp revealed a close relatedness of Aspergillus flavus and Fusarium sp to Fusarium redolens strainTIST190421511 (Figure 4). 
Table 2: Cultural and Morphological Characteristics of fungal isolates

\begin{tabular}{|c|c|c|}
\hline \multicolumn{3}{|c|}{ Characteristics } \\
\hline $\begin{array}{l}\text { Fungal } \\
\text { Isolate }\end{array}$ & Cultural & Morphological \\
\hline $\begin{array}{l}\text { Aspergillus } \\
\text { flavus }\end{array}$ & $\begin{array}{l}\text { Colonies are granular, flat, often with radial } \\
\text { grooves, yellow at first but quickly becoming } \\
\text { bright to dark yellow-green with } \\
\text { age. Conidial heads are typically radiate, later } \\
\text { splitting to form loose columns biseriate but } \\
\text { having some heads with phialides borne directly } \\
\text { on the vesiclecleistothecia }\end{array}$ & $\begin{array}{l}\text { Conidiophore stipes are hyaline and coarsely } \\
\text { roughened, often more noticeable near the } \\
\text { vesicle. Conidia are globose to subglobose }\end{array}$ \\
\hline $\begin{array}{l}\text { Fusarium } \\
\text { redolens }\end{array}$ & $\begin{array}{l}\text { Colonies growing slowly; surface usually orange } \\
\text { to deep apricot due to confluent conidial slime; } \\
\text { aerial mycelium sometimes floccose and } \\
\text { whitish. }\end{array}$ & $\begin{array}{l}\text { Conidiophores loosely branched, with short, } \\
\text { often swollen phialides. Macroconidia } \\
\text { strongly curved and pointed at the apex, } \\
\text { mostly one septate, Microconidia absent }\end{array}$ \\
\hline
\end{tabular}

Table 3: Cultural, Morphology and Biochemical characteristics of Bacterial Isolates

\begin{tabular}{|c|c|c|c|c|c|c|c|c|c|}
\hline \multicolumn{10}{|c|}{ Biochemical test } \\
\hline Cultural & Gramstain & Cat & Nit & Coa & Gel & Ure & Glu & Suc & Inference \\
\hline $\begin{array}{l}\text { Brown on MaC and Greenish } \\
\text { Colonies on NA }\end{array}$ & - & + & + & - & + & - & + & - & $\begin{array}{l}\text { Pseudomonas } \\
\text { aeruginosa }\end{array}$ \\
\hline Purple on MaC & - & + & + & - & + & - & + & + & $\begin{array}{l}\text { Enterobacter } \\
\text { asburiae }\end{array}$ \\
\hline
\end{tabular}

KEY: Cat-catalase, Nit- nitrate, Coa-coagulase, Gel-gelatin, Ure- urea, Glu- glucose, Suc-srucose

Table 4: Occurrence of bacteria and fungi isolated from soil samples

\begin{tabular}{|l|c|c|c|c|c|}
\hline \multicolumn{3}{|c|}{ Farm Locations } & Occurrence (\%) \\
\hline & A & B & C & D & \\
\hline Enterobacter asburiae & + & + & - & + & $(75.0 \%)$ \\
\hline Pseudomonas aeruginosa & + & + & + & + & $(100 \%)$ \\
\hline Aspergillus flavus & + & & & & \\
\hline Fusarium redolens & - & + & + & + & $(75.0 \%)$ \\
\hline
\end{tabular}




\section{$12 \mathrm{~N} \mathrm{~L}$}

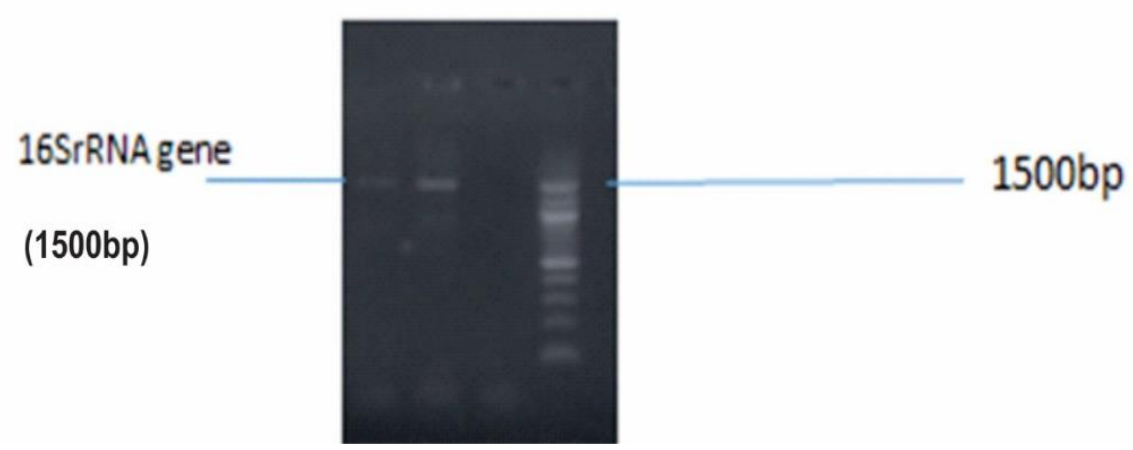

Figure 1: Agarose gel electrophoresis of the 16S rRNA gene of Pseudomonas aeruginosa and Enterobacter asburiae. Lanes 1-2 represent the 16SrRNA gene bands (1500bp). Lane N represents the negative control; lane $\mathrm{L}$ represents the $100 \mathrm{bp}$ molecular ladder.

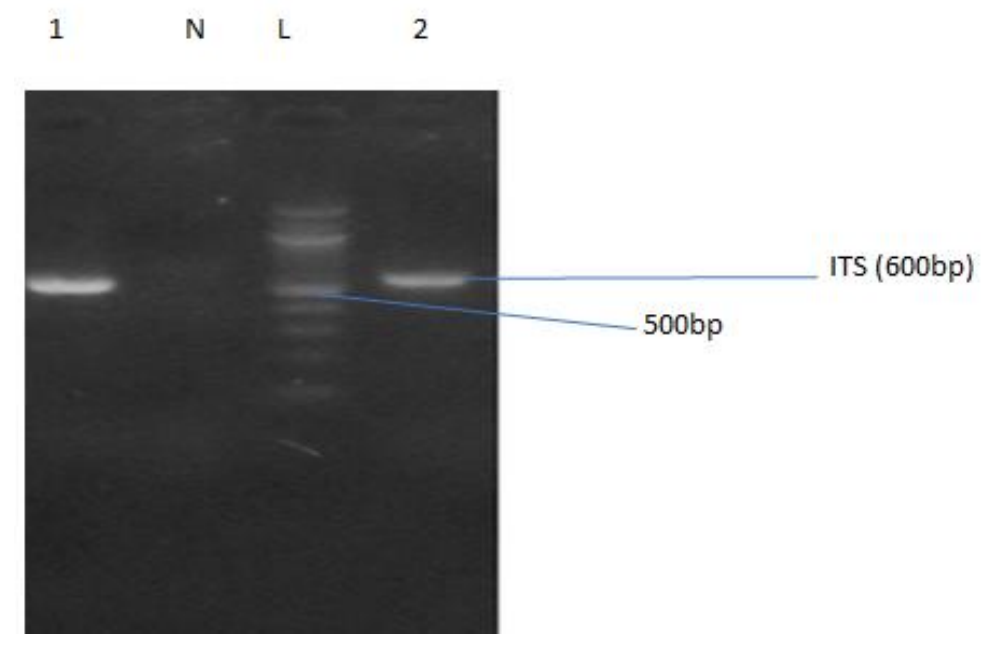

Figure 2: Agarose gel electrophoresis showing the amplified ITS fragment of Aspergillus flavus and Fusarium Redolens. Lanes $1-2$ represent the ITS bands at $600 \mathrm{bp}$ while $\mathrm{N}$ represent negative control, lane $\mathrm{L}$ represents the $100 \mathrm{bp}$ molecular ladder.

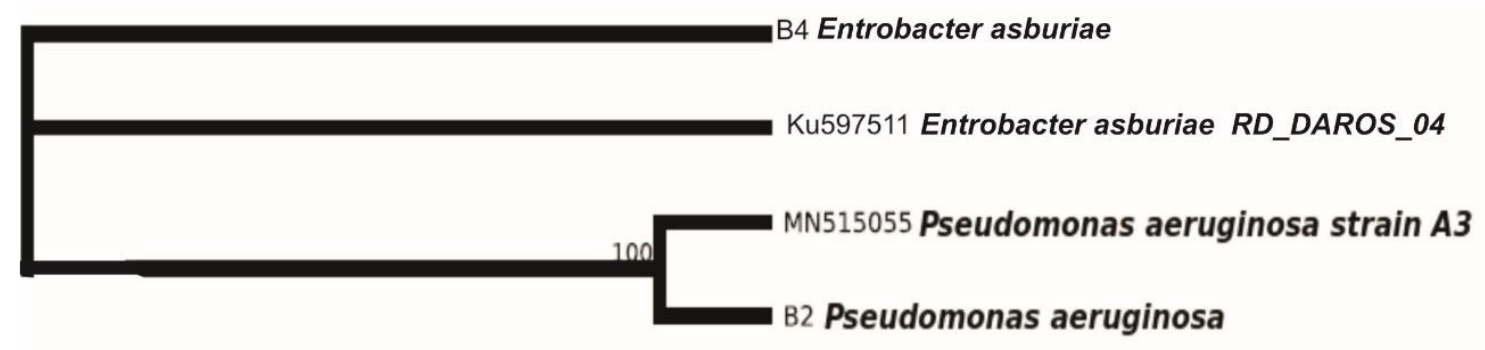

Figure 3: Phylogenetic tree showing the evolutionary distance between the bacterial isolates 


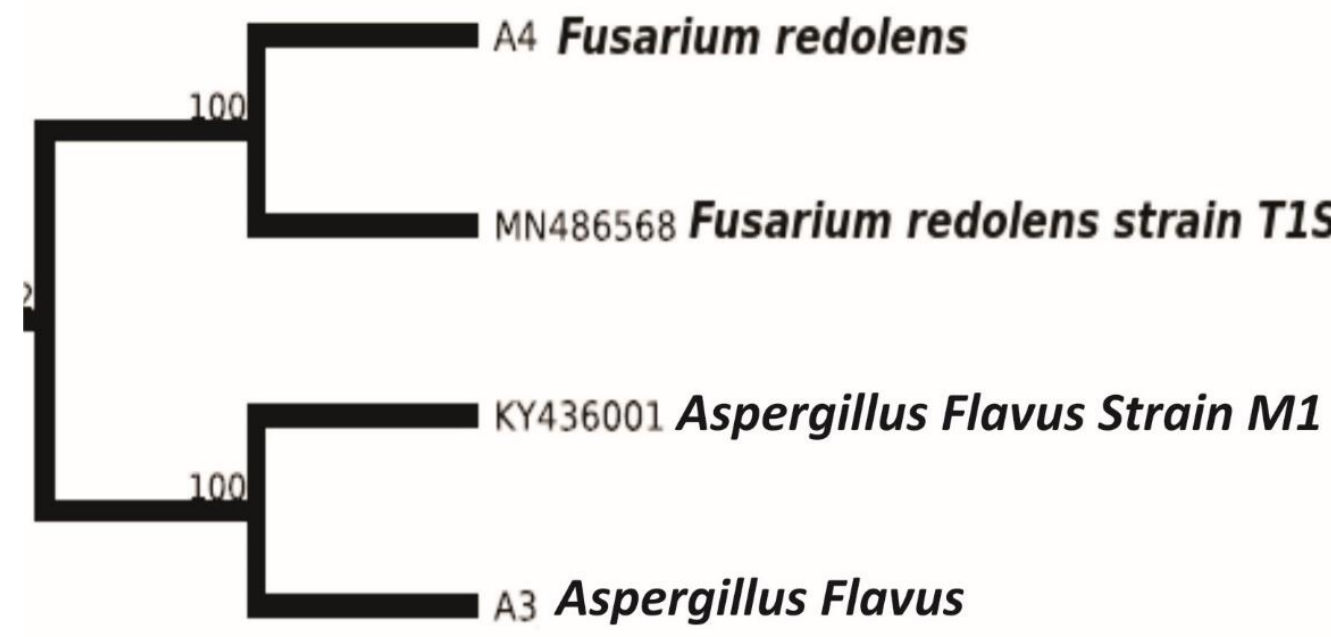

Figure 4: Phylogenetic tree showing the evolutionary distance between the fungi isolates

\subsection{Discussion}

Pollution of soil and water by herbicide is known to cause serious damage to micro and macro flora and fauna of the soil, aquatic and human [20]. This study focuses on the identification of herbicidedegrading bacteria and fungi species isolated from the farmland soil in Keffi, area of Nassarawa State, Nigeria.

The bacteria and fungi species isolated from the soil environment in Keffi were Enterobacter asburiae, Pseudomonas aeruginosa, Aspergillus flavus, and Fusarium redolens. The isolation of bacteria and fungi as mentioned were in agreement with the study earlier reported by Olukanmi et al., [20], Singh et al., [21], and Samarth et al., [22].

The occurrences of bacteria and fungi mentioned above suggest that the microorganism may be resistant to herbicide present in the soil. Members of the genus Pseudomonas are known to possess a wide range of degradative activities [23] and have the ability to develop new degradative activities [24].

Congeevaram et al., [25] reported that cells of certain organisms are negatively charged due to the presence of anionic structure and this gives microorganisms the ability to band chemical compounds and absorbed it into the cell. The utilization of herbicide content of medium by bacteria and fungi isolates such as Enterobacter asburiae, Pseudomonas aeruginosa, Aspergillus flavus, Fusarium redolens as observed in this study was totally in agreement with the study earlier described by Olukanmi et al. [20].

\subsection{Conclusion}

In conclusion, the present study revealed that bacteria strains of Pseudomonas aeruginosa strain CIFRI DTSB1 and Entrobacter asburiae RD-DAROS04 and the fungi isolates including the Aspergillus flavus and Fusarium redolens under the phylogenic tree of Fusarium redolens strainTIST190421511 were the major microbial habitant of pesticidecontaminated farmland in Keffi, and thus represent the herbicide degrading microorganism in this region. Further analysis on the herbicide degrading properties of these microbial strain is underway

Acknowledgement: Our appreciation goes to Dr. D. Ishaleku, Prof. Y. B. Ngwai, and all the lecturers of the Microbiology Department, Nasarawa State University, Nigeria

Author's contributions: Study design; methodology; data collection, original draft writing. Prof. Makut MD: Supervisor; reviewed draft and edited the manuscript. All authors read and approved the final version of the manuscript

Conflict of interest statement: The authors hereby declare that there is no conflict of interest from any of them.

Funding: This work received no external funding 
Institutional Review Board Statement: Not Applicable.

Informed Consent Statement: Not Applicable.

\section{References}

1. Torsvik, V.; Øvreås, L. Microbial diversity and function in soil: from genes to ecosystems. Current opinion in microbiology 2002, 5, 240-245.

2. Nannipieri, P.; Ascher, J.; Ceccherini, M.; Landi, L.; Pietramellara, G.; Renella, G. Microbial diversity and soil functions. European journal of soil science 2003, 54, 655-670.

3. Willey, J.M.; Sherwood, L.; Woolverton, C.J. Prescott's microbiology; McGraw-Hill New York: 2011; Vol. 7.

4. Makwin, M.D.; Opemipo, M.O. Bioremediation potentials of chicken droppings on crude oil polluted soil from automobile workshop. GSC Biological and Pharmaceutical Sciences 2019, 8, -.

5. Majekodunmi, O.O.; Makut, M.D.; King, M.A.; Rahinat, G.; Majiyebo, A.J.; Damola, A.S. Biostimulation Potentials Of Chicken Dropping On Spent Oil Contaminated Soil From Automobile Workshorps In Keffi, Nasarawa State Nigeria. AEJ 2020.

6. Sims, G.; Radosevich, M.; He, X.; Traina, S. The effects of sorption on the bioavailability of pesticides. In Biodegradation, Springer: 1991; pp. 119-137.

7. Sondhia, S. Herbicides residues in soil, water, plants and non-targeted organisms and human health implications: an Indian perspective. Indian journal of weed science 2014, 46, 66-85.

8. Landrigan, P.J.; Benbrook, C. GMOs, herbicides, and public health. The New England journal of medicine 2015, 373, 693-695.

9. Bukowska, B. Toxicity of 2, 4Dichlorophenoxyacetic Acid--Molecular Mechanisms. Polish Journal of Environmental Studies 2006, 15.
10. Karigar, C.S.; Rao, S.S. Role of microbial enzymes in the bioremediation of pollutants: a review. Enzyme research 2011, 2011.

11. Aislabie, J.; Lloyd-Jones, G. A review of bacterial-degradation of pesticides. Soil Research 1995, 33, 925-942.

12. Anderson, J. Herbicide degradation in soil: influence of microbial biomass. Soil Biology and Biochemistry 1984, 16, 483-489.

13. Singh, B.; Singh, K. Microbial degradation of herbicides. Critical reviews in microbiology 2016, 42, 245-261.

14. Makut, M.; Bello, A. Assessment of the Biodegradation of Herbicides by Bacteria Isolated from the Soil. Asian Journal of Biotechnology and Bioresource Technology 2018, 1-6.

15. Damalas, C.A.; Eleftherohorinos, I.G. Pesticide exposure, safety issues, and risk assessment indicators. International journal of environmental research and public health 2011, 8, 1402-1419.

16. Makut, M.; Ekeleme, I. Citric Acid Production by Aspergillus niger and Trichoderma viride Using Hydrolysed Potato Peels Substrate. Asian Journal of Advances in Agricultural Research 2018, 1-7.

17. Saitou, N.; Nei, M. The neighbor-joining method: a new method for reconstructing phylogenetic trees. Molecular biology and evolution 1987, 4, 406-425.

18. Felsenstein, J. Evolutionary trees from DNA sequences: a maximum likelihood approach. Journal of molecular evolution 1981, 17, 368-376.

19. Jukes, T.H.; Cantor, C.R. Evolution of protein molecules. Mammalian protein metabolism 1969, 3, 21-132.

20. Olukanni, D.O.; Akinyinka, O.O.; Ede, A.N.; Akinwumi, I.I. Appraisal of municipal solid waste management, its effect and resource potential in a semi-urban city: a case study. Journal of South African Business Research 2014, 2014, 1-13. 
21. Singh, S.; Kumar, V.; Singh, J. Kinetic study of the biodegradation of glyphosate by indigenous soil bacterial isolates in presence of humic acid, $\mathrm{Fe}$ (III) and $\mathrm{Cu}$ (II) ions. Journal of Environmental Chemical Engineering 2019, 7, 103098.

22. Samarth, D.P.; Chandekar, C.J.; Bhadekar, R.K. Biosorption of heavy metals from aqueous solution using Bacillus licheniformis. International Journal of Pure and Applied Sciences and Technology 2012, 10, 12.

23. STANIER, R.Y.; Palleroni, N.J.; Doudoroff, $M$. The aerobic pseudomonads a taxonomic study. Microbiology 1966, 43, 159-271.

24. Kellogg, S.; Chatterjee, D.; Chakrabarty, A. Plasmid-assisted molecular breeding: new technique for enhanced biodegradation of persistent toxic chemicals. Science 1981, 214, 1133-1135.
25. Congeevaram, S.; Dhanarani, S.; Park, J.; Dexilin, M.; Thamaraiselvi, K. Biosorption of chromium and nickel by heavy metal resistant fungal and bacterial isolates. Journal of hazardous materials 2007, 146, 270-277.

\section{Submit your article to AROC JOURNALS -AROC in Pharmaceutical and Biotechnology -AROC in Agriculture -AROC in Food and Nutrition -AROC in Natural Product Research -BIOMED Natural and Applied Science Via https://arocjournal.com/}

